\title{
O DIREITO À SAÚDE NA INTERFACE ENTRE SOCIEDADE CIVIL E ESTADO
}

\author{
THE RIGHT TO HEALTHCARE AT THE INTERFACE BETWEEN CIVIL SOCIETY AND STATE
}

Felipe Rangel de Souza Machado ${ }^{1}$

Resumo O objetivo deste artigo é discutir sobre o desenvolvimento do direito à saúde no Brasil. Parte-se do processo de construção dos direitos sociais, passando pela assunção destes direitos na Carta Magna Brasileira até chegar às compreensões atuais de certos segmentos sociais sobre o direito à saúde. A análise baseia-se na pesquisa realizada em Porto Alegre, Rio Grande do Sul, a respeito da atuação conjunta entre conselhos de saúde e Ministério Público. Pode-se observar que o direito à saúde tem sido associado à ideia de acesso a serviços de saúde. Isto, no entanto, tem se mostrado ser um aspecto limitador na luta pela garantia e ampliação deste direito. Por este motivo, determinados segmentos da sociedade vêm adotando uma postura mais ativa em relação à compreensão sobre este direito. Tal compreensão tem rendido ganhos substanciais na luta pela ampliação do direito à saúde no Brasil. Assim, explicitar as diferentes concepções sobre o direito à saúde de um conselho de saúde que tem se demonstrado atuante no cenário nacional pode dar indícios sobre as formas de atuação possíveis e as estratégias desenvolvidas nestas instituições para a garantia deste direito.

Palavras-chave direito à saúde; conselhos de saúde; direitos sociais.
Abstract The objective of this paper is to discuss the development of the right to healthcare in Brazil. It begins with the process of creating social rights, going from the rise of these rights in the Brazilian Constitution until reaching the current understandings of certain social groups concerning the right to healthcare. The analysis is based on research conducted in Porto Alegre, state of Rio Grande do Sul, in regards to the joint action between health councils and the Public Ministry. It can be observed that the right to healthcare has been associated with the idea of access to healthcare services. This, however, has been shown to be a limiting aspect in the fight for the security and expansion of this right. For this reason, certain groups of society have taken on a more active attitude regarding the understanding of this right. This understanding has yielded substantial gains in the struggle for the expansion of the right to healthcare in Brazil. Furthermore, detailing the different concepts about the right to healthcare of a healthcare council that has proven to be active in the national scenario, may give indications of the possible forms of action and strategies developed in these institutions to guarantee this right.

Keywords right to healthcare; healthcare councils; social rights. 


\section{Introdução}

Tradicionalmente, a ideia de direito à saúde no Brasil tem se resumido a uma concepção de acesso aos bens e serviços de saúde. No entanto, essa concepção se choca com a própria história de luta pela afirmação do direito à saúde como direito de cidadania (conforme exigia o Movimento pela Reforma Sanitária). Essa redução está ligada, em parte, à histórica definição de direitos sociais, pautada na prestação de alguns serviços à população.

Na contramão deste entendimento, a Constituição do 1988, afirma a saúde como "direito de todos e dever do Estado". O artigo 3 da Lei Orgânica da Saúde (lei n. ${ }^{\circ} 8.080 / 90$ ) define como fatores determinantes condicionantes da saúde a "alimentação, a moradia, o saneamento básico, o meio ambiente, o trabalho, a renda, a educação, o transporte, o lazer e o acesso aos bens e serviços essenciais". Portanto, uma definição bem mais ampla do que a restrita noção de acesso aos serviços de saúde.

Apesar de sua abrangente definição constitucional, o direito à saúde vem sendo concebido como um dos muitos pilares do direito do consumidor. Associar, no entanto, saúde a consumo implica, necessariamente, numa discussão sobre o mercado, o que transforma, fatalmente, o Sistema Único de Saúde (SUS) em um plano de saúde. Se, por um lado, essa inflexão possibilita, por exemplo, a requisição do acesso a bens e serviços de saúde na justiça, por outro retira a saúde do rol dos direitos difusos e coletivos (na medida em que o mercado o individualiza) e o reduz a ações pontuais, não comportando, portanto, os determinantes e condicionantes prezados pela Lei Orgânica.

Este é um dilema que tem sido enfrentado tanto pelos diversos setores sociais quanto pelas muitas esferas de governo. Ao mesmo tempo que se garante o direito individual a bens específicos em saúde, também se limita a possibilidade da ampliação do direito à saúde ao conjunto da sociedade, e, principalmente, limita-se a ampliação da própria concepção sobre saúde. Embora haja a garantia imediata de determinados insumos e bens e saúde pela via judicial, neste modelo o direito à saúde tende a se apequenar, se limitar em relação à sua amplitude constitucional. No interior da concepção do direito à saúde como algo individual, existe, implicitamente, uma ideia de que, como os recursos são invariavelmente escassos, ou seja, não estão disponíveis para o conjunto da sociedade, devem ser garantidos àqueles que o buscam. Assim, o direito individual é garantido e, ao mesmo tempo, é excluída essa mesma possibilidade de uma outra parcela da população.

Ao contrário desta perspectiva, a luta coletiva pelo direito à saúde tem ampliado seu escopo de reivindicações. Dessa forma, se, no passado, lutavase, por exemplo, por acesso a consultas médicas, hoje se reivindica a dispensação de medicamentos. A segunda luta não constitui uma substituição da 
primeira, mas sua própria ampliação, pois abarca novas necessidades e demandas. A saída para o dilema da gestão dos recursos escassos pode estar no acirramento da construção de espaços efetivos de participação popular. Espaços estes que sejam parte integrante da gestão em saúde (Silva, Pinheiro e Machado, 2003).

Os conselhos de saúde têm desempenhado um papel importante nesta discussão, todavia não exercem a função principal de mediação deste embate. Muitas vezes são inoperantes, outras são aparelhados e, ainda em outras, são ignorados. Apenas em poucas situações exercem um papel central, o que não lhes tira, de forma alguma, a importância de suas funções. Talvez a estratégia dos conselhos não deva ser vista como a única forma possível de inserção social no campo da saúde, mas possa ser articulada com outras propostas e iniciativas. Ressalta-se que a criação de uma cultura participativa não pode ser feita por decretos, mas construída cotidianamente, processo que pode levar mais tempo do que o tempo de existência do próprio SUS. Tal cultura participativa tem o potencial de se desenvolver de forma diferente nos diversos estados brasileiros. Assim, o Rio Grande do Sul, por exemplo, é um estado historicamente marcado por uma intensa movimentação social, característica que se observa na atuação dos conselhos de saúde (Silva, Pinheiro e Machado, 2003, 2004).

Não é intenção, neste momento, explicar a formação da sociedade brasileira e o desenvolvimento da cidadania, mas devemos, minimamente, atentar para a história política brasileira desde pelo menos a Proclamação da República, profundamente marcada por períodos antagônicos e alternados de fortes ditaduras e frágeis democracias. Este processo histórico, como nos têm mostrado diversos pensadores sociais brasileiros de diferentes épocas, é expressão de uma visão de mundo peculiar não apenas à política no Brasil, mas à própria constituição de nossa sociedade civil. ${ }^{2}$ Apenas a partir de 1987, com a eleição da Assembleia Constituinte, iniciou-se um sólido ciclo democrático, experiência ainda muito recente se compararmos com outros países democráticos.

O objetivo deste artigo é realizar uma discussão teórica a respeito da constituição dos direitos sociais e apresentar as concepções sobre o direito à saúde de integrantes do Conselho Estadual de Saúde do Rio Grande do Sul. Este texto tem sua origem na dissertação de mestrado intitulada Direito à saúde, integralidade e participação: um estudo sobre as relações entre sociedade e Ministério Público na experiência de Porto Alegre. ${ }^{3}$ A pesquisa que possibilitou a confecção desta dissertação foi de cunho eminentemente qualitativo, de caráter exploratório. As técnicas privilegiadas de coleta de dados foram entrevistas em profundidade e análise de documentos institucionais.

Antes, porém, de se tratar especificamente do objetivo específico deste texto, é necessária uma rápida revisão teórica a respeito de alguns temas 
importantes para a constituição da questão do direito. Assim, nosso objeto privilegiado refere-se aos direitos sociais, entendidos como um dos aspectos mais fundamentais de qualquer sociedade moderna no mundo ocidental, pilar do Estado-Nação e embrião das democracias contemporâneas.

\section{Questões históricas}

A ideia de Estado Democrático de Direito relaciona-se à necessidade de superação das desigualdades sociais e regionais e à instauração de um regime democrático que, efetivamente, realize a justiça social. Para tanto, é necessário ampliar a noção de Estado de Direito tradicionalmente limitada à sua definição formal, como o 'governo de leis', mas compreendê-lo como um Estado material de Direito, em que estejam reconhecidos ao mesmo tempo, como meta, parâmetro e limite da atividade estatal, certos valores, direitos e liberdades fundamentais, superando, desta forma, uma noção que se limita a garantir determinadas formas e procedimentos da organização do poder e das competências dos órgãos estatais.

Os direitos fundamentais constituem critérios de legitimação do poder estatal e, por conseguinte, da própria ordem constitucional, na medida em que "o poder se justifica por e pela realização dos direitos do homem e que a ideia de justiça é hoje indissociável de tais direitos" (Pinto apud Sarlet, 2002, p. 68). Funda-se, desta forma, um profundo entrelaçamento entre os direitos fundamentais e o Estado de Direito. Não se trata tanto de justificar a origem e a fundamentação destes direitos. Como argumenta Bobbio (1992), a discussão a respeito da justificação da origem desses direitos perde sentido com a adoção nas últimas décadas, pela maioria dos países, de uma declaração universal dos direitos do homem. "É preciso que se esteja convencido de que a realização dos direitos do homem é uma meta desejável; mas não basta essa convicção para que aquelas condições se efetivem" (Bobbio, 1992, p. 23). Essa meta desejável estabelece uma ligação inequívoca entre as competências do Estado e os interesses sociais. Sarlet (2002), utilizando uma citação de Pérez Luño, insiste na existência de um nexo de interdependência entre o Estado de Direito e os direitos fundamentais, "uma vez que o Estado de Direito exige e implica, para sê-lo, a garantia dos direitos fundamentais, ao passo que estes exigem e implicam para sua realização, o reconhecimento e a garantia do Estado de Direito" (Sarlet, 2002, p. 69).

Embora com frequência se utilize indiferenciadamente os termos 'direitos humanos' e 'direitos sociais' ou 'direitos fundamentais', é necessário diferenciá-los pelos seus próprios processos de construção histórica. De acordo com Sarlet (2002, p. 37), direitos fundamentais caracterizam-se por serem precisos e restritos, pois são constituintes do conjunto de direitos e 
liberdades reconhecidos institucionalmente pelo Estado e garantidos pelo direito positivo, referindo-se, portanto, a direitos determinados no espaço e no tempo, “cuja denominação se deve ao seu caráter básico e fundamentador do sistema jurídico do Estado de Direito". Já o termo 'direitos humanos' diz respeito a uma noção internacional que reconhece o ser humano como tal - a partir da concepção de humanidade -, independentemente de sua vinculação constitucional, referindo-se, portanto, a todos os povos e tempos.

Não há dúvidas da existência de uma vinculação entre os dois tipos de direitos, pois o titular dos direitos fundamentais sempre será um ser humano. Porém, determinado Estado pode não garantir certos direitos fundamentais aos seus cidadãos, o que não lhes tira a condição de ser humano. A adoção dos direitos fundamentais pelas constituições dos Estados aconteceu muito tempo depois de serem reconhecidos os direitos humanos e, como salientou Bobbio (1992, p. 5), ocorreu por diversas lutas históricas, "não todos de uma vez, nem de uma vez por todas". A noção da conquista de novos direitos nos remete a outra concepção do campo jurídico: as 'gerações' dos direitos.

Embora autores como Sarlet (2002) prefiram a denominação 'dimensão' dos direitos em contraposição à 'geração' (de acordo com ele, o segundo termo indica uma ideia de substituição e não de ampliação), será utilizado, para fins de exposição, o termo empregado por Bobbio (1992): 'as gerações do direito'. Trataremos neste texto dos mais relevantes, quais sejam os direitos fundamentais de primeira e de segunda gerações.

De acordo com a leitura de Sarlet (2002), o reconhecimento, nas primeiras constituições escritas, de tais direitos fundamentais é produto do pensamento liberal burguês do século XVIII, notadamente de cunho individualista. Externava-se desta maneira a necessidade de delimitação de uma zona de não intervenção do Estado, caracterizando-se como direito de defesa, demarcando uma esfera de autonomia individual frente ao poder do Estado.

Por este motivo, são apresentados como direitos de cunho 'negativo', ou seja, para sua efetivação é necessária a não intervenção dos poderes públicos, sendo, neste sentido, "direitos de resistência ou de oposição perante o Estado" (Sarlet, 2002, p. 54). Destacam-se, no rol desses direitos, os direitos à vida, à liberdade, à propriedade e à igualdade perante a lei. Posteriormente, foram complementados por uma gama de liberdades, incluindo as liberdades de expressão coletiva (liberdades de expressão, imprensa, manifestação, reunião, associação etc.), e pelos direitos de participação política (o direito de voto). Para o autor, isso revelou "íntima correlação entre os direitos fundamentais e a democracia" (Sarlet, 2002, p. 55).

A inserção dos direitos sociais nas constituições dos Estados nacionais modernos foi inspirada por duas correntes preponderantes do pensamento ocidental que se estabeleceram definitivamente na segunda metade 
do século XVIII a partir de episódios históricos marcantes, como a Independência dos Estados Unidos (1776), a Revolução Industrial inglesa e a Revolução Francesa (1789). Essas duas correntes seriam a anglo-saxã e a francesa (suscitadas, no primeiro caso, por pensadores liberais, como John Stuart Mill e John Locke e, no segundo, por Montesquieu e Rousseau). Em linhas gerais, a primeira corrente se distinguiria da segunda por sua ênfase na sociedade como projeção dos indivíduos, ao passo que, nesta última, o indivíduo cederia lugar ao cidadão, criação da sociedade política, isto é, do Estado. A noção de que os direitos individuais teriam precedência e, por conseguinte, proeminência sobre os direitos sociais, isto é, no jargão tautológico do direito, de que os direitos de primeira geração viriam, 'naturalmente', em primeiro lugar, e os de segunda geração, em segundo, provém primordialmente da tradição anglo-saxã, fonte de um dos mais conceituados teóricos do direito do último século, T. H. Marshall.

Os direitos fundamentais de primeira geração, segundo Bonavides (apud Sarlet, 2002), são os direitos de liberdade e igualdade formal, os primeiros a constarem na normatividade constitucional. Seriam os chamados direitos civis e políticos, que correspondem, historicamente, à fase inaugural do constitucionalismo ocidental, nunca tendo deixado de postular nas constituições até os dias de hoje. O paradigma dos direitos da primeira geração foi o principal ponto de embates até o início do século XX, a partir de então foram engendrados novos direitos fundamentais.

Dado que o século XIX foi marcado pelo advento dos direitos da primeira geração (direitos civis e políticos), o decorrer do século XX caracterizou-se por uma nova ordem social. A simples garantia formal da liberdade e igualdade não gerava frutos para todas as classes sociais, sobretudo à imensa massa trabalhadora explorada no capitalismo da época.

De acordo com Bobbio (1992), os direitos individuais tradicionais constituem-se em 'liberdades', já os chamados direitos sociais consistem em 'poderes'. O autor explica que 'liberdades' referem-se aos direitos garantidos quando o Estado não intervém 4 (a atuação negativa do Estado) e 'poderes', aos direitos que exigem uma intervenção do Estado para sua efetivação. Neste raciocínio, liberdades e poderes são incompatíveis, e não complementares, como se crê frequentemente. "A sociedade histórica em que vivemos, caracterizada por uma organização cada vez maior em vista da eficiência, é uma sociedade em que cada dia adquirimos uma fatia de poder em troca de uma fatia de liberdade" (Bobbio, 1992, p. 44).

Esta nova ordem social apresenta uma estruturação dos direitos fundamentais não mais sedimentada no individualismo do modelo anterior, mas requer, ao contrário, a cessão de uma parte da individualidade em troca de garantias sociais. A diferenciação destes direitos está em sua 'dimensão positiva', uma vez que se trata "não mais de evitar a intervenção do Estado na 
esfera da liberdade individual, mas, sim, (...) de propiciar um 'direito' de participar do bem-estar social” (Sarlet, 2002, p. 55). Estes direitos caracterizam-se por propiciarem aos indivíduos direitos a prestações sociais estatais, como saúde, educação, trabalho etc.

Os direitos fundamentais da segunda geração se tornam, portanto, tão essenciais quanto os direitos fundamentais da primeira geração, seja por sua universalidade quanto por sua eficácia. Assim, são caracterizados como os direitos sociais, culturais e econômicos, bem como os direitos coletivos ou de coletividades, introduzidos no constitucionalismo das distintas formas de Estado social.

Os direitos da segunda geração estão profundamente relacionados aos chamados direitos prestacionais sociais do Estado para com o cidadão. É dever do Estado garantir determinados 'serviços' à sociedade. Estes direitos passam a incluir o rol de poderes da sociedade, caracterizando-se como uma certa passagem das liberdades formais abstratas para os poderes materiais concretos.

A marca desta nova fase dos direitos fundamentais não está somente no fato de estes direitos terem o escopo positivo, mas, principalmente, por caracterizarem-se como 'liberdades sociais', como, por exemplo, liberdade de sindicalização, do direito de greve etc. Em resumo, o direito à saúde integra os direitos fundamentais da segunda geração, pois exige do Estado prestações positivas para, deste modo, evidenciar a sua garantia e efetividade, sendo chamado, portanto, de direito social prestacional. Talvez por isso, a noção de direito à saúde tenha se aproximado da ideia de garantia de acesso a bens e serviços de saúde. Compreender o direito à saúde como direito de cidadania vai além de uma discussão formal ou jurídica.

\section{Cidadania e direitos civis: percursos históricos}

Para Marshall (1967), haveria um certo curso 'natural' para o alargamento da cidadania, iniciado com o estabelecimento dos direitos civis, pois a formalização dos direitos relativos à liberdade individual representa uma condição necessária para a ruptura com o feudalismo e a emergência do capitalismo. Neste sentido, em primeiro lugar, dever-se-ia garantir a liberdade de propriedade privada e a liberdade de trabalho. Então, seria possível afirmar que é razoavelmente mais fácil garantir os direitos de liberdade ao invés dos direitos sociais, pois, para a garantia dos primeiros, caberia ao Estado apenas a 'omissão', enquanto para a garantia dos segundos restaria forçosamente a 'intervenção' direta. O campo jurídico, 'nesses moldes', discrimina a ação do Estado com vistas à garantia do primeiro grupo de direitos de 'ação negativa' e, para o segundo, de 'ação positiva'. A ação negativa do 
Estado visaria à 'manutenção' da liberdade de propriedade privada e da igualdade jurídica entre os indivíduos; já a ação positiva se destinaria a 'instituir' condições mínimas de existência, como a saúde, a educação, o trabalho etc. Tal explicação, no entanto, deve ser examinada com cuidado, uma vez que pode induzir graves equívocos.

A afirmação de que a garantia dos direitos de liberdade é 'razoavelmente mais fácil' de se obter do que a dos direitos sociais não apenas omite os porquês dessa pretensa razoabilidade como a naturaliza. Se existe uma tal facilidade, como de fato pode ser constatada, as condições que a possibilitam devem ser perscrutadas. Uma ordem hierárquica que pressupõe a prioridade dos direitos de liberdade sobre os direitos sociais não é um fenômeno isolado e, muito menos, um dado da natureza. Suas origens remetem, indissociavelmente, à formação do Estado de Direito moderno, que, por sua vez, é um produto constitutivo da sociedade capitalista ocidental.

Historicamente, a garantia dos direitos de igualdade jurídica não foi uma evolução natural do direito, assim como não o foi, para a sociedade ocidental, a constituição da propriedade privada. Ambos os processos advieram de rupturas sociais, muito embora, em seus primórdios, tais instituições modernas tenham, inegavelmente, guardado vestígios característicos das instituições que as precederam - o feudo e o jusnaturalismo absolutista -, porém regidos agora por uma lógica completamente distinta (Polanyi, 2000). É, portanto, no mínimo ingênuo, imaginar que o Estado é 'omisso' na 'manutenção' dos direitos de liberdade. O Estado jamais mostrou-se omisso, pois, como parte essencial na conformação da sociedade capitalista moderna, foi uma engrenagem extremamente 'atuante' na 'instauração' dos pressupostos materiais de tais direitos - a propriedade privada e o trabalho assalariado.

O Estado moderno ocidental constitui, ao mesmo tempo, alvo e trampolim de um intenso esforço revolucionário burguês, cujas maiores expressões foram, incontestavelmente, em primeiro lugar, a Revolução Francesa (na qual o Estado foi objeto de domínio indispensável para a criação dos direitos de igualdade jurídica, fundamentais na consolidação do 'livre contrato de trabalho') e, em segundo lugar, a Revolução Industrial inglesa (na qual o Estado foi o principal impulsionador da grande indústria moderna). Assim, a proteção dos direitos de liberdade, longe de ser a tarefa 'razoavelmente mais fácil', foi a mais árdua conquista da burguesia - desde as grandes navegações até o Imperialismo Colonial. A preponderância desses direitos sobre os sociais não apenas é arbitrária, no sentido de nãonatural, como também é um fenômeno de origem histórica definível. Em contrapartida, a suposta dificuldade em garantir o cumprimento dos direitos sociais revela-se, sob esta ótica, como a expressão mais crua do interesse das classes dominantes. Pensar em propostas transformadoras que alcem os 
direitos sociais ao mesmo grau de importância dos ditos direitos de liberdade passa, portanto, pela crítica das condições sociais que presidem essa discrepância hierárquica. Tal crítica, todavia, pode adquirir diversas feições no decorrer das lutas sociais, em resposta às circunstâncias políticas concretas de um determinado contexto histórico.

No Brasil a instauração de direitos sociais constituiu, em determinado momento, uma condição para a limitação ou mesmo a supressão dos direitos civis e políticos. Já nos Estados Unidos, os direitos civis e políticos estabeleceram-se simultaneamente no momento da elaboração da Constituição. As duas experiências demonstram a inexistência de uma sequência lógica necessária à expansão da cidadania. O estabelecimento da cidadania resulta, portanto, de correlações de forças e das condições estruturais, próprias a cada formação social e histórica, e não diz respeito à democracia em geral.

Os direitos sociais, conquistados no plano legal com a redemocratização no Brasil, não encontraram meios nem espaços de realização na nova esfera pública regida pela lógica de redução dos gastos públicos, obediente ao novo papel desempenhado pelo Estado de gestor da dívida pública e de avalista do capital internacional. Se, no período da ditadura militar, os direitos sociais foram migalhas de uma promessa de bolo jamais repartido entre a população, na nova ordem democrática eles são considerados, já de antemão, anseios economicamente inalcançáveis, embora desejáveis e legítimos. Bobbio (1992, p. 24) convida a recordar que "o mais forte argumento adotado pelos reacionários de todos os países contra os direitos do homem, particularmente contra os direitos sociais, não é a sua falta de fundamento, mas sua inexequibilidade". De acordo com o autor, a enunciação destes direitos congrega diversos atores, sendo o acordo, portanto, obtido com relativa facilidade, independentemente do poder de convicção de seu fundamento absoluto. Entretanto, no momento de passar da teoria sobre os direitos à ação, ainda que seu fundamento seja inquestionável, começam as reservas e oposições.

O desamparo social da maior parte da população brasileira, ainda que remonte a uma época longínqua, permanece até os dias de hoje quase totalmente inalterado, desde a passagem do regime autoritário para o democrático. Todavia, os movimentos sociais, longe de terem desenvolvido uma ação inócua, possibilitaram a inserção da maioria de seus projetos societários na Constituição brasileira. Apesar de a herança legal deixada por esses atores sociais não ter se revertido, automaticamente, em conquistas materiais, ela cimentou o alicerce sobre o qual toda a sociedade civil pôde se edificar. 


\section{A saúde como um direito fundamental social}

No Brasil, a adoção constitucional de uma compreensão mais ampliada de direitos, os direitos da segunda geração, proporciona ao Estado momentos de profundas contradições, justamente pela já mencionada nova lógica de atuação do Estado. O arcabouço legal que justificava a intervenção do Estado na vida particular, apenas para manter a ordem, passava agora a conviver com normas que exigiam iniciativas estatais positivas de justiça distributiva mediante políticas econômicas e sociais que garantissem os novos direitos de natureza metaindividual.

$\mathrm{O}$ direito à saúde aparece mencionado em diversos pontos da nossa Constituição. Além disso, existem vários outros direitos afins, que se relacionam diretamente com o direito à saúde. Como já mencionado, de acordo com a Constituição, "a saúde tem como fatores determinantes e condicionantes, entre outros, a alimentação, a moradia, o saneamento básico, o meio ambiente, o trabalho, a renda, a educação, o transporte, o lazer e o acesso aos bens e serviços essenciais".

Esta concepção de direito à saúde, como já mencionado, tem encontrado inúmeras dificuldades para se tornar realidade, gerando posições contrárias à afirmação constitucional da saúde como direito de todos e dever do Estado. Tenta-se, neste sentido, caracterizar a saúde como uma 'norma programática', de forma que "ao invés de se definir em fins concretos a serem alcançados, contém princípios e programas (tanto de conduta quanto de organização), bem como princípios relativos a fins a cumprir existem apenas na esfera constitucional" (Sarlet, 2002, p. 286).

A assunção do direito à saúde como norma programática, mais do que uma simples discussão sobre terminologias, constitui uma tentativa de desonerar o Estado de suas funções precípuas, indo de encontro à própria noção de Estado Democrático de Direitos. Esta lógica perversa choca-se com os próprios anseios presentes no movimento que deu origem ao SUS. A nova hermenêutica constitucional se desataria de seus vínculos com os fundamentos e princípios do Estado Democrático de Direito se os relegasse ao território das chamadas normas programáticas, recusando-lhes concretude sem a qual a dignidade da pessoa humana não passaria de ilusória e mera abstração (Sarlet, 2002). É importante destacar ainda que mesmo a saúde sendo um atributo individual (conferindo, portanto, a cada pessoa o direito de exigir do Estado condições para gozar de boa saúde) sua garantia é realizável apenas por meios coletivos. Não é possível garantir condições de saúde a um indivíduo isolado sem que esta garantia seja extensiva para todos aqueles que partilham com ele o mesmo ambiente.

Ao observarmos as falas dos conselheiros de saúde, percebemos o nível desta perspectiva 'ampliada' do direito à saúde. Na fala citada a seguir, de 
um conselheiro de saúde representante de uma comunidade rural, fica claro que a discussão a respeito da garantia constitucional do direito à saúde não figura mais no rol de discussão do conselho, considerada uma questão superada. ${ }^{5}$ Assim, o entrevistado apresenta novas questões a serem debatidas. Percebe-se neste sentido que esta fala, de forma alguma isolada, exemplifica a discussão sobre a ampliação do direito. Representa, ainda, uma elevada maturidade política na percepção dos problemas e nas suas estratégias de resolução.

Agora a gente aumentou o leque da discussão; agora a gente não está só nas causas geradoras de doenças, aquela coisa que a gente tem os direitos constitucionais do cidadão, que são os princípios do SUS. A gente abraçou isso e o SUS tem dois lados: tem a qualidade de vida e tem a assistência médica hospitalar, que é um direito constitucional que brigamos para conseguir. E consequentemente vieram outras lutas, como a emenda constitucional n. ${ }^{\circ} 29$. Só que eu acho que isto é uma outra questão que tem que ser discutida junto com a capacitação dos conselheiros para se entender a gestão. Então, quer dizer que agora a gente não está mais só discutindo fazer xarope e pomada, todas essas coisas comunitárias, a saúde para dentro da porteira. A gente agora está trazendo toda essa questão para fora da porteira e questionando essa relação ao SUS. Não podemos ficar preocupados só e exclusivamente com a doença. Nós temos que questionar e nos preocupar também com o SUS como qualidade de vida. E qualidade de vida significa emocional, física, mental, essas coisas todas. Então, quer dizer, a gente vem de um mundo pequeno e abriu o leque, e cada vez mais vem aumentando o leque (Conselheiro de saúde A).

A citação a seguir complementa a perspectiva anterior e aponta para outro fator também muito presente nas falas dos conselheiros: o direito à informação em saúde. Além disso, traz consigo a ideia do imposto pago pela sociedade como fundamento legítimo do direito. Devemos atentar, contudo, que, diferentemente do que pode parecer num primeiro olhar, a associação do direito ao imposto não caracterizará o usuário como consumidor. Pelo contrário, a afirmação presente na fala enfatiza uma dimensão coletiva desse 'pagar imposto', exigindo do Estado um retorno em serviços de qualidade. Portanto, o direito à saúde não é defendido como mais uma das faces do 'direito do consumidor', mas, na medida em que exige do Estado uma boa aplicação da parcela de contribuição da sociedade para a própria manutenção do Estado, está, desta maneira, acirrando sua postura de cidadão e afirmando que a saúde é um direito de cidadania. Nesta mesma perspectiva, Luz (1991, p. 86) aponta para a tomada de consciência por parte da sociedade civil sobre o papel da saúde e das instituições médicas na vida coletiva, “a compreensão deste papel foi muito importante, pois tornou 
claro que são os próprios trabalhadores que financiam, através de impostos, os serviços médicos, que deveriam, antes de tudo, servi-los".

Direito à saúde é tudo. Direito à saúde não é só saúde, é habitação, é educação, é segurança, é alimentação, é tudo. Porque não adianta tu ter o remédio e não ter o que comer, não resolve nada. Não adianta tu não ter educação e $t u$ não saber que aquilo lá que $t u$ tá pisando, $t u$ não ter entendimento que $t u$ tá pisando no meio do esgoto é saúde. O rato passando por cima dos teus filhos é saúde. Então, isso é saber o que é direito à saúde. Então $t u$ tem que ter direito sim, se $t u$ tiver passando um valão no teu pátio, os órgãos públicos têm que sanear aquilo ali, é o saneamento básico, isso é o direito à saúde. É ter o direito de ter onde morar, porque $t u$ vai para essas favelas e não tem nada. $T u$ tem direito à água, tem direito a tudo, e isso é saúde. E não é favor, é direito que a gente tem porque paga os impostos. Então esse é o direito que eu entendo (Conselheiro de saúde B).

Um outro grupo de interpretação defende o direito à saúde numa dimensão filosófica, como uma condição própria aos seres humanos em geral:

O direito à saúde é inerente à pessoa humana. Acho que todos nós temos o direito de sermos tratados humanamente. Isso aí é um direito pela Constituição do cidadão. (Conselheiro de saúde C).

Além disso, o entrevistado defende a inserção da participação social como condição para a garantia deste direito. Para ele, a Constituição do Estado não tem condições de, sozinha, garantir toda a amplitude do direito à saúde.

É, eu vejo que o Estado, o ente Estado, já está mais do que provado que ele sozinho não faz nada. Bem, aí tu vai dizer: "Mas a gente tem toda uma estrutura de assembleias, câmaras, todo o quadro enorme de funcionários..." (Conselheiro de saúde C) .

Apesar da justificação do direito à saúde como direito fundamental não mais constituir objeto de debate dos conselhos na localidade estudada, esta mesma questão permanece como ponto sem solução em outras localidades. Diante disso, decisões do Supremo Tribunal Federal6 têm respaldado a perspectiva de saúde como um direito fundamental, ao lado dos direitos individuais e políticos e do direito de nacionalidade.

De acordo com os dispositivos da Constituição Federal de 1988, o direito à saúde deve ser compreendido (e adotado) como um direito social fundamental. Diz respeito à preservação da vida e ao respeito à dignidade humana, sendo sua garantia requisito fundamental ao alcance da justiça social. 
Atribuiu-se às ações e aos serviços de saúde o caráter de relevância pública. A alteração de tal preceito depende de amplo e rígido processo legislativo.

O artigo 196 da Constituição Federal de 1988 é claro ao estabelecer a saúde como um direito de todos e dever do Estado. A ação do Estado é a condição fundamental para a efetivação do direito à saúde. Desta forma, não se deve impor limites à garantia da saúde dos cidadãos. Nenhum dos entes federados tem o direito de eximir-se de tal obrigação. $\mathrm{O}$ direito à saúde apresenta como pressuposto o direito assegurado pela Constituição: todas as pessoas podem exigir do Estado condições de gozar de boa saúde. O direito à saúde como garantia constitucional tem feito parte do repertório dos conselheiros de saúde e constitui premissa de suas atuações.

Primeiro, direito à saúde é constitucional. E acho que cada vez mais a população está sabendo disso. Então, acho que o que está na Constituição de que a saúde é um direito do cidadão e um dever do Estado, acho que as pessoas tão se conscientizando disso. Mesmo as pessoas que não participam, que não sabem aonde recorrer, se vão ao conselho, se vão à rádio, se vão ao vereador, já têm consciência disso. Eu acredito que o SUS se consolidou nesses anos. Acho que nesse período de adolescência do SUS ele já está reconhecido pela população e as pessoas fazem valer mesmo. E acho que a cidadania está reconhecendo esse seu direito, que o Estado, independente da esfera de governo, que seja municipal, estadual, federal ou que seja uma entidade filantrópica, tem que estar proporcionando este seu direito (Conselheiro de saúde D).

Dallari et al. (1996, p. 540), numa pesquisa com conselheiros de saúde, já apontava para o fato de que "o discurso mais recorrente com relação ao direito à saúde se refere a algo inerente ao ser humano, que numa visão jusnaturalista sobrepõe a existência do Estado ou das leis, mas que cabe ao primeiro garanti-lo". Dessa forma, os conselheiros de saúde entrevistados compreendiam as leis "como um importante instrumento, que deve ser utilizado para fazer valer o direito" (Dallari et al., 1996, p. 540).

A justificativa da gestão, no entanto, para a não garantia desses direitos tem sido sempre a reafirmação da escassez de recursos. Além disso, argumenta-se, costumeiramente, que os poucos recursos disponíveis devem ser utilizados com os mais pobres da sociedade. Esta lógica, inicialmente, parece justa, entretanto, não questiona o próprio limite financeiro do Estado. Como alerta Mattos (2005, p. 45), “é fundamental que os gestores acolham o desafio de ir além da simples gerência dos recursos escassos, para se engajar na discussão com os poderes no seu nível de governo, com as instâncias de pactuação e com a sociedade civil como um todo".

A lógica dos recursos escassos pode ser percebida também, embora em outros termos, nas falas dos usuários, em contraposição aos relatos anteriores. 
Para estes, os poucos recursos devem ser disponibilizados àqueles que se encontram em maior grau de vulnerabilidade. Observa-se, ainda, a relação estabelecida entre o direito à saúde e a disponibilização de acesso a serviços médicos. Limitar a ideia de direito à saúde à garantia de acesso é reproduzir a lógica que, ao invés de ampliar as ações do Estado, as retrai ao nível mínimo de atuação. Chamar a atenção para este fato é fundamental, pois, no limite, esta lógica pode contribuir para a concretização da ideia de que saúde pública é caridade para populações em estado de indigência e miséria. Apesar de existir a concepção do 'SUS para miserável' (que não é exclusiva das classes populares), dentro dos conselhos de saúde isto vem se modificando. O relato pessoal de um conselheiro exemplifica isso:

E a gente estava cansado de dizer que SUS é para miserável e não é para miserável. Eu conheço muita gente que tem isso aqui [faz sinal com os dedos indicando dinheiro] e está lá no SUS, porque o único que faz transplante é o SUS. Nenhum plano privado faz transplante. Então, mesmo que as pessoas tenham muito dinheiro utilizam o SUS também. Tem muita gente que tem convênios caros e vai lá no posto de saúde buscar o medicamento, porque se pagar o convênio não tem dinheiro para o remédio. Então, a gente conscientiza as pessoas a exercerem a sua cidadania, dizerem que não estão pedindo favor, que é um direito legítimo (Conselheiro de saúde B).

Embora haja uma ambivalência de interpretações sobre os legítimos destinatários dos serviços de saúde pública, a atuação do conselho, como um todo, tem assumido uma postura de agir sob o preceito constitucional de que 'saúde é direito de todos e dever do Estado', sem se limitar a discutir o que é possível dentro dos recursos disponíveis. Esta atuação tem apresentado grandes avanços em termos de cidadania participativa, pois tem obrigado o Estado a estender sua atuação a esferas antes vistas como inviáveis.

Direito à saúde é inerente. Para ter vida. E o que é que é ter vida? Ter vida é desde o momento que eu seja concebido. Quer dizer, existem os direitos todos da manutenção, da qualidade de vida, esse é um direito que tu tens. E isso face ao direito à saúde, eu digo não só nos atos puramente médicos, que deixamos transparecer durante a conversa, os atos médicos de diagnósticos, de exames, medicação, de prevenção através de vacinas, de educação, mas da participação intrínseca, e aí eu volto àquela minha participação, as participações de tantos de nós que fazemos saúde, no conceito de saúde que se tem, dentro de movimentos populares para brigar, por exemplo, por aumento de salários. Para brigar, por exemplo, o que adianta eu falar que $t u$ tem que tomar mebendazol para aquela verminose, se aquela criança está bebendo água poluída ou está metendo o pé no lixo que tem ali dentro. Então, isso é básico. Que a água não seja poluí- 
da, que o meio ambiente não seja destruído. Assim, direito à saúde é um direito e nós entramos agora cada vez mais num entendimento (Conselheiro de saúde B).

\section{Considerações finais}

A condição primordial para o desenvolvimento de qualquer regime democrático é a vida do ser humano, até porque, relembrando mais uma vez a Constituição, “os níveis de saúde da população expressam a organização social e econômica do País", expressam inclusive o grau de democratização deste país no que diz respeito à distribuição de seus recursos pelos seus cidadãos. A garantia do direito à saúde não pode ser colocada em segundo plano nas ações dos Estados e muito menos deve servir como discursos, promessas e moeda de troca nas eleições nacionais.

Os direitos são construções sociais marcadas por lutas entre diferentes interesses possíveis em um momento histórico (Bobbio, 1992). A definição do conteúdo do direito à saúde não ocorreu e nem ocorre de forma tranquila e passiva. Pelo contrário, requer de cada situação um processo de negociação política, desde o cotidiano dos serviços básicos de saúde até as resoluções no Legislativo e Executivo. Caracteriza-se, desta forma, como uma luta de hegemonias. Isto é mais visível ao atentarmos para o fato de que a inscrição do direito à saúde como um direito de cidadania na Carta Magna foi possível apenas por uma movimentação da sociedade civil que lutou para fazer-se presente historicamente no sentido de "exigir do estado, geralmente quase arrancar, direitos políticos, econômicos e sociais de cidadania" (Luz, 2000, p. 297).

Por fim, cabe reafirmar a importância do direito à saúde, pois este se revela como condição fundamental para o exercício dos outros direitos sociais. Sua garantia, conforme versa a Constituição, é referencial de desenvolvimento econômico e social do país. Ao adotarmos o direito à vida como um valor a ser defendido, assumimos o direito à saúde como ponto indiscutível das políticas sociais, como característica 'indispensável' no exercício da cidadania. Explicitar as diferentes concepções sobre o direito à saúde de um conselho de saúde que tem se demonstrado atuante no cenário nacional pode nos dar indícios sobre as formas de atuação possíveis e as estratégias desenvolvidas nestas instituições para a garantia deste direito. ${ }^{7}$ 


\section{Notas}

1 Professor-pesquisador da Escola Politécnica de Saúde Joaquim Venâncio, da Fundação Oswaldo Cruz (EPSJV/Fiocruz), Rio de Janeiro, Brasil. Doutorando em Saúde Coletiva pelo Instituto de Medicina Social da Universidade do Estado do Rio de Janeiro (IMS/Uerj).<felipemachado@fiocruz.br>

Correspondência: Fundação Oswaldo Cruz, Escola Politécnica de Saúde Joaquim Venâncio, Avenida Brasil, 4.365, Manguinhos, Rio de Janeiro, Brasil, CEP 21040-900.

2 Autores como Gilberto Freire, Sérgio Buarque de Holanda - que trataram da herança patriarcal do Brasil colonial incutida em nossas instituições -, Florestan Fernandes, Caio Prado Jr. e Celso Furtado - que se detiveram sobre questões da formação econômica brasileira e a profunda desigualdade social e estagnação da mobilidade entre classes no país - apontaram diferentes caminhos para a compreensão desse fenômeno.

3 Dissertação apresentada no IMS/Uerj, desenvolvida no escopo de pesquisa do Laboratório de Pesquisas de Práticas de Integralidade em Saúde (Lappis), com auxílio da Fundação Carlos Chagas Filho de Amparo à Pesquisa do Estado do Rio de Janeiro (Faperj) e do Conselho Nacional de Desenvolvimento Científico e Tecnológico (CNPq).

4 Estamos adotando aqui a terminologia dos autores ao se referirem à não intervenção estatal.

5 Ressalta-se que a superação da discussão não aconteceu pela garantia efetiva do acesso a determinados insumos e serviços de saúde, mas pela superação da concepção teórica sobre o direito à saúde. O patamar de discussão no conselho não se limita mais ao acesso a esses insumos e serviços. Diz respeito atualmente a uma concepção mais ampliada de saúde.

6 Ver, por exemplo, Recurso Extraordinário em Mandado de Segurança, externado na peça de n. $^{\circ} 11.183 / \mathrm{PR}$, no voto do relator ministro José Delgado; julgamento do Recurso Extraordinário 271.286-RS no voto do relator ministro Celso de Mello, em ambos os casos os ministros afirmam que a saúde não pode constituir-se como norma programática. A jurisprudência tem afirmado que a saúde é um direito fundamental social do homem, visto que o direito à saúde tem aplicabilidade imediata e eficácia plena.

7 Para compreender as estratégias adotadas por este conselho na garantia do direito à saúde, ver Machado (2006).

\section{Referências}

BOBBIO, Norberto. A teoria do ordenamento jurídico. São Paulo: UNB, 1992.

BODSTEIN, Regina Cele. A cidadania e modernidade: emergência da questão social na agenda pública. Cadernos de Saúde Pública, v. 13, n. 2, p. 185-204, abr.-jun. 1997.

CAMPILONGO, Celso Fernandes. O trabalhador e o direito à saúde: a eficácia das normas 
jurídicas de proteção à saúde do trabalhador. Série Informes Técnicos, n. 19, p. 15, 1992.

COHN, Amélia. Estado e sociedade e as reconfigurações do direito à saúde. Ciência \& Saúde Coletiva, v. 8, n. 1, p. 9-18, 2003.

COHN, Amélia et al. A saúde como direito e como serviço. São Paulo: Cortez, 1999.

DALLARI, Sueli Gandolfi. Os estados brasileiros e o direito à saúde. São Paulo: Hucitec, 1995.

DALLARI, Sueli Gandolfi et al. O direito à saúde na visão de um conselho municipal de saúde. Cadernos de Saúde Pública, Rio de Janeiro, v. 12, n. 4, p. 531-540, 1996.

LUZ, Madel Therezinha. Notas sobre as políticas de saúde no Brasil de 'transição democrática': anos 80. Physis - Revista de Saúde Coletiva, v. 1, n. 1, p. 77-95, 1991.

Duas questões permanentes em um século de políticas de saúde no Brasil republicano. Cadernos de Saúde Pública, v. 5, n. 2, p. 293-312, 2000.

MACHADO, Felipe Rangel de Souza. Direito à saúde, integralidade e participação: um estudo sobre as relações entre Sociedade e Ministério Público na experiência de Porto Alegre, 2006. Dissertação de Mestrado, Rio de Janeiro: Instituto de Medicina Social, Universidade do Estado do Rio de Janeiro.

MARSHALL, Thomas Humphrey. Cidadania, classe social e status. Rio de Janeiro, Zahar, 1967.

MATTOS, Rubem Araújo de. Os sentidos da integralidade: algumas reflexões acerca de valores que merecem ser defendidos. In: PINHEIRO, Roseni; MATTOS, Rubem Araújo de. Os sentidos da integralidade na atenção e no cuidado à saúde. Rio de Janeiro: IMS/Uerj, 2001.

Direito, necessidades de saúde e integralidade. In: PINHEIRO, Roseni;
MATTOS, Rubem Araújo de. Construção social da demanda: direito à saúde, trabalho em equipe, participação e espaços públicos. Rio de Janeiro: Cepesc/Uerj, Abrasco, 2005.

MOURA, Erly Catarina. Direito à saúde: o papel de diferentes sujeitos sociais no exercício da cidadania. Saúde e Sociedade, v. 5, n. 1, p. 109-129, 1996.

NOGUEIRA, Vera Maria Ribeiro, PIRES, Denise Eliva. Direito à saúde: um convite à reflexão. Cadernos de Saúde Pública, v. 13, n. 2, p. 753-760, 1997.

POLANYI, Karl. A grande transformação: as origens da nossa época. 2. ed. Rio de Janeiro: Campos, 2000.

SARLET, Ingo Wolfgang. A eficácia dos direitos fundamentais. Porto Alegre: Livraria do Advogado, 2002.

SILVA, José Paulo V. da; PINHEIRO, Roseni; MACHADO, Felipe Rangel de S. Necessidades, demanda e oferta: algumas contribuições sobre os sentidos, significados e valores na construção da integralidade na reforma do Setor Saúde. Saúde em Debate, n. 65 , v. 27, p. 234-242, set.-dez. 2003.

Integralidade como inovação institucional - a experiência da Secretaria de Saúde/RS, 1999-2002: considerações sobre a gestão no SUS. Revista de Administração Pública, n. 3, v. 38, p. 481-500, maio/jun. 2004.

TELLES, Vera da Silva. Direitos sociais: afinal do que se trata?. Belo Horizonte: UFMG, 1999.

WENDHAUSEN, Águeda; CAPONI, Sandra. O diálogo e a participação em um conselho de saúde em Santa Catarina, Brasil. Cadernos de Saúde Pública, v. 18, n. 6, p. 1.621-1.628, nov./dez. 2002.

Recebido em 12/02/2008

Aprovado em 28/05/2008 